\title{
Antibacterial Activity of Pomegranate (Punica granatum L.) Seed and Peel Alcoholic Extracts on Staphylococcus aureus and Pseudomonas aeruginosa Isolated From Health Centers
}

\author{
Yaser Nozohour', Reza Golmohammadi ${ }^{*}$, Reza Mirnejad', Majid Fartashvand ${ }^{2}$ \\ ${ }^{1}$ Molecular Biology Research Center, Systems Biology and Poisonings Institute, Baqiyatallah University of Medical Sciences, Tehran, \\ Iran \\ ${ }^{2}$ Department of Clinical Sciences, Faculty of Veterinary Medicine, Tabriz Branch, Islamic Azad University, Tabriz, Iran
}

Corresponding Author: Reza Golmohammadi, Molecular Biology Research Center, Systems Biology and Poisonings Institute, Baqiyatallah University of Medical Sciences, Tehran, Iran. Tel/Fax: +98-21-88039883, Email: rsr.golmohammadi@bmsu.ac.ir

Received December 10, 2017; Revised February 5, 2018; Accepted February 10, 2018; Online Published March 30, 2018

\begin{abstract}
Introduction: Pomegranate (Punica granatum L.) is an ancient fruit with numerous phytochemical bioactive compounds. In this study, the antibacterial activity of ethanolic extracts of pomegranate peels and seeds were investigated against Pseudomonas aeruginosa and Staphylococcus aureus clinical isolates from Tabriz health centers (2017).

Materials and Methods: The ethanolic extracts of pomegranate seed and peel were prepared and GC-MS chromatogram analyzed using Agilent $7890 \mathrm{~B}$ gas chromatography. The antibacterial activities of extracts were evaluated by agar diffusion and microbroth dilution methods against clinical isolates of $P$. aeruginosa $(n=10), S$. aureus $(n=10)$ and standard strains.

Results: The ethanolic extracts of pomegranate seed and peel showed inhibitory effects on clinical isolates of $P$. aeruginosa and $S$. aureus. The minimum inhibitory concentrations (MICs) of pomegranate peel and seed extracts were 12.5 and $25.0 \mathrm{mg} / \mathrm{mL}$, respectively. In addition, the minimum bactericidal concentrations (MBCs) of pomegranate peel and seed extracts were found to be 25.0 and $50 \mathrm{mg} / \mathrm{mL}$, respectively. In all of the studied bacterial isolates, the MICs and MBCs values for pomegranate seed extract were significantly higher than those for pomegranate peel extract $(P<0.05)$. The mean inhibition zones and MICs values indicated that the antibacterial activity of pomegranate peel extract had more potent effect on studied bacterial isolates compared with pomegranate seed extract.

Conclusions: According to the findings, the pomegranate peel and seed extracts showed antibacterial activities against bacterial isolates in this study; however, the peel extract had a stronger antibacterial effect than the seed extract. Therefore, further studies including cell toxicity assay and in vivo investigations are recommended.

Keyword: Antibacterial Effect, Alcoholic Extracts, Punica granatum L., Staphylococcus aureus, Pseudomonas aeruginosa

Citation: Nozohour Y, Golmohammadi R, Mirnejad R, Fartashvand M. Antibacterial activity of pomegranate (Punica granatum L.) seed and peel alcoholic extracts on Staphylococcus aureus and Pseudomonas aeruginosa isolated from health centers. J Appl Biotechnol Rep. 2018;5(1):32-36. doi:10.29252/jabr.01.01.06.
\end{abstract}

\section{Introduction}

Resistance to antimicrobial drugs in pathogenic bacteria is a global concern. ${ }^{1-3}$ Pseudomonas aeruginosa and Staphylococcus aureus are important nosocomial pathogens, which both frequently cause multidrug resistance. ${ }^{1,4}$ Infections caused by commercial antibiotic resistance isolates have increased greatly during the last decades in hospitals. ${ }^{2}$ The spread of these organisms in healthcare settings are often difficult to control, due to the presence of multiple intrinsic and acquired mechanisms of antimicrobial resistance.,

In recent years, study of antibacterial properties of plant extracts is of interest. ${ }^{6}$ Pomegranate (Punica granatum L.) is a native fruit in Iran that is rich in phytochemical compounds with myriad biological properties therefore it has a rich history of traditional use in medicine. ${ }^{7}$ Pharmacological effects of pomegranate have been mentioned anciently and research on pomegranate is increasing due to its great nutritional values and medicinal uses. ${ }^{8}$ In several studies it had been found that pomegranate extracts have many potential effects including antibacterial, ${ }^{9}$ antifungal, ${ }^{10}$ antiviral ${ }^{11}$ and some other activities.

The aim of this study was to assess the potential antibacterial activity of $P$. granatum L. seed and peel alcoholic extracts against $P$. aeruginosa and $S$. aureus clinically isolated from health centers of Tabriz.

\section{Materials and Methods}

Extraction

Fresh pomegranate fruits were purchased from a local market. The sample was authenticated by Pharmacognosy department. The peels and seeds of pomegranate were removed manually, 
air-dried at room temperature, and ground into powder by a hammer mill with 80 sizes. To prepare the extract, $200 \mathrm{~g}$ of each powder was soaked in $70 \%$ ethanol solution (1:10 ratio) in a closed container and was shaken for 24 hours at dark room. The extracts were filtered through Whatman No. 41 filter paper and concentrated under vacuum at $40^{\circ} \mathrm{C}$ using a rotary machine, and the obtained powder was stored at $-80^{\circ} \mathrm{C}$ and later used..$^{12,13}$ The ethanolic extracts of pomegranate seed and peel were analyzed using Agilent 7890B gas chromatography coupled to a 5977A series mass spectrometer equipped with a split/splitless injection system and an electron bombardment ionization model, and had MS library for NIST and WILEY. Samples were injected into the GC-MS on a 30-m silica capillary column with internal diameter and film thickness of $0.25 \mathrm{~mm}$ and $0.25 \mu \mathrm{m}$, respectively. The GC temperature was set to increase from $60^{\circ} \mathrm{C}$ to $290^{\circ} \mathrm{C}$ at a rate of $15^{\circ} \mathrm{C} / \mathrm{min}$ and finally held isothermal for 1 minute (split ratio $1: 100$ ).

\section{Isolation and Identification of Bacteria}

The assayed microorganisms used in this study were as follows: (1) Local clinical isolates: P. aeruginosa $(\mathrm{n}=10)$ and $S$. aureus $(\mathrm{n}=10)$ obtained from microbiological laboratories of health centers of Tabriz. (2) Reference strains: P. aeruginosa PTCC 1430 and S. aureus PTCC 1112. The strains were identified by the use of biochemical profiles according to the recommendations of the Manual of Clinical Microbiology. ${ }^{14}$

\section{Assay for Antibacterial Activity}

The antibacterial activities of extracts were evaluated using agar disk-diffusion ${ }^{9}$ and microbroth dilution. ${ }^{15,16}$ The minimum inhibitory concentration (MIC) and minimum bactericidal concentration (MBC) were determined. Bacterial suspensions equivalent to a 0.5 McFarland turbidity were prepared in sterile normal saline solution from clinical and reference isolates. A sterile swab dipped into the inoculum tube containing bacterial suspensions and then was cultured on the Müller-Hinton agar (Merck ${ }^{\circledR}$, Germany). Sterile filter paper disc (6 $\mathrm{mm}$ in diameter) were impregnated with pomegranate seeds and peels extracts $(30 \mu \mathrm{L})$ for $10-15$ minutes and allowed to dry completely for 20-25 minutes, then evenly placed on the surface of previously inoculated cultures. Tetracycline and chloramphenicol antibiotic discs (Merck ${ }^{\circledR}$, Germany) were positive controls and sterile diluent ( $0.1 \%$ peptone water) was negative control for comparison of inhibition zone with sample. Plates were incubated at $37^{\circ} \mathrm{C}$ for 24 hours, until visible growth of bacteria was evident in control plates. Clearly visible inhibition zones around discs were measured in 3 directions and averaged. The antibacterial activity was expressed according to the diameter of inhibition zone produced by extract against test bacteria.

\section{Determination of $\mathrm{MIC} / \mathrm{MBC}$}

The broth microdilution method was performed to determine the MICs and MBCs values. Each well of microplate was filled with a total volume of $100 \mu \mathrm{L}$ containing Müller-Hinton broth (MHB). Different concentrations of each extract were prepared by serial dilution in MHB. One hundred microliters of inoculums contains approximately $5 \times 10^{5} \mathrm{CFU} / \mathrm{mL}$ of test bacteria was added to each well. Negative controls contained non-inoculated medium with extract samples, and positive control wells were prepared with inoculated culture medium with no extracts. Resazurin powder (Sigma-Aldrich) was diluted in distilled water to a final concentration of $1 \mathrm{mg} / \mathrm{mL}$ and $10 \mu \mathrm{L}$ was added to all wells. Microplates were incubated at $37^{\circ} \mathrm{C}$ for 24 hours. The MIC was determined by observing the lowest concentration of extract which would inhibit visible growth of bacteria. ${ }^{15}$ For determination of MBC, $20 \mu \mathrm{L}$ of the suspension of Well before MIC of the extract were cultured on BHI agar using the spread plate technique. The MBC were evaluated by counting the number of bacterial colonies after 24 hours of incubation at $37^{\circ} \mathrm{C} . .^{16}$

\section{Statistical Analysis}

Each test was repeated in triplicate and all parameters were measured in duplicate. The mean and standard deviation (SD) of the growth inhibition zone diameter in agar diskdiffusion method as well as the MIC and MBC of the extracts, tetracycline and chloramphenicol were determined. Data were analyzed using Statistical Package for Social Sciences for Windows, version 19.0 (SPSS Inc.). Statistical significance was identified at the 95\% confidence level $(P<0.05)$.

\section{Ethical Considerations}

This article is from a research project which was approved by the Ethics Committee of the Baqiyatallah University of Medical Sciences.

\section{Results}

According to high-performance liquid chromatography (HPLC) analysis, we found similar phytochemical constituents in both ethanolic extracts of pomegranate peel and seed. Details are shown in Table 1 and Figures 1-2).

The ethanolic extracts of pomegranate seed and peel showed inhibitory effects on the growth and proliferation of clinical isolates of $P$. aeruginosa and $S$. aureus (Table 2), which were potent than tetracycline and chloramphenicol $(P<0.01)$. The largest diameter of growth inhibition zone (most sensitivity) belonged to peel extract of pomegranate on the both $P$. aeruginosa and $S$. aureus.

The MICs and MBCs values of $P$. aeruginosa and $S$. aureus were determined as evaluation of the antimicrobial activity of the pomegranate cultivars and presented in Table 3. The MICs of pomegranate peel and seed extracts were 12.5 and $25.0 \mathrm{mg} / \mathrm{mL}$, respectively. In addition, the MBCs of pomegranate peel and seed extracts were found to be 25.0 and $50 \mathrm{mg} / \mathrm{mL}$, respectively. In all of the studied bacteria MICs for pomegranate seed extract were significantly higher than those for pomegranate peel extract $(P<0.05)$. Similarly, the $\mathrm{MBC}$ values for pomegranate seed extract were higher than pomegranate peel extract, but only for $P$. aeruginosa were statistically significant.

\section{Discussion}

In this study, both pomegranate seed and peel extracts showed antibacterial activities against $S$. aureus and $P$. aeruginosa. The mean inhibition zones and MICs values indicate that the 
Table 1. Main Phytochemicals Identified in the Ethanolic Extracts of the Pomegranate Peel and Seed

\begin{tabular}{|c|c|c|c|c|c|}
\hline \multirow{2}{*}{ No } & \multirow{2}{*}{ Name } & \multirow{2}{*}{ Formula } & \multirow{2}{*}{ Retention time } & \multicolumn{2}{|c|}{ Percent } \\
\hline & & & & Seed & Peel \\
\hline 1 & Furfural & $\mathrm{C}_{5} \mathrm{H}_{4} \mathrm{O}_{2}$ & 3.63 & 6.57 & 2.97 \\
\hline 2 & Heptacosane & $\mathrm{C}_{27} \mathrm{H}_{56}$ & 19.15 & 22.39 & 38.98 \\
\hline 3 & 5-Hydroxymethylfurfural & $\mathrm{C}_{6} \mathrm{H}_{6} \mathrm{O}_{3}$ & 9.78 & 12.19 & 9.25 \\
\hline 4 & Ellagic acid & $\mathrm{C}_{14} \mathrm{H}_{6} \mathrm{O}_{8}$ & 10.38 & 7.27 & 8.62 \\
\hline 5 & Ellagic acid, 3,3'-di-O-methyl & $\mathrm{C}_{16} \mathrm{H}_{10} \mathrm{O}_{8}$ & 7.81 & 2.63 & 3.04 \\
\hline 7 & Punicalagin & $\mathrm{C}_{48} \mathrm{H}_{28} \mathrm{O}_{30}$ & 6.42 & 0.52 & 2.13 \\
\hline 8 & Pyrogallol & $\mathrm{C}_{6} \mathrm{H}_{6} \mathrm{O}_{3}$ & 10.14 & 2.08 & 5.31 \\
\hline 9 & Gallic acid & $\mathrm{C}_{7} \mathrm{H}_{6} \mathrm{O}_{5}$ & 12.91 & 11.95 & 8.30 \\
\hline 10 & Catechin & $\mathrm{C}_{15} \mathrm{H}_{14} \mathrm{O}_{6}$ & 6.80 & 0.53 & 1.86 \\
\hline 11 & Epicatechin & $\mathrm{C}_{15} \mathrm{H}_{14} \mathrm{O}_{6}$ & 7.20 & 2.49 & 4.30 \\
\hline 12 & Gallocatechin & $\mathrm{C}_{15} \mathrm{H}_{14} \mathrm{O}_{7}$ & 6.08 & 1.09 & 0.14 \\
\hline 14 & Ascorbic acid & $\mathrm{C}_{6} \mathrm{H}_{8} \mathrm{O}_{6}$ & 15.81 & 5.92 & 3.13 \\
\hline 15 & Linoleic acid & $\mathrm{C}_{18} \mathrm{H}_{32} \mathrm{O}_{2}$ & 18.45 & 9.70 & 2.16 \\
\hline 16 & Stigmasterol & $\mathrm{C}_{29} \mathrm{H}_{48} \mathrm{O}$ & 28.22 & 0.82 & 0.05 \\
\hline 17 & Gamma-sitosterol & $\mathrm{C}_{29} \mathrm{H}_{50} \mathrm{O}$ & 28.63 & 5.25 & 0.12 \\
\hline
\end{tabular}

antibacterial activity of pomegranate peel extract was higher than pomegranate seed extract. The antimicrobial activity of various extracts or pure compounds from the different parts of pomegranate plant had been studied previously and different results were reported by different researchers.

In a study carried out by Malviya et al, methanolic and ethanolic extracts of pomegranate showed inhibition zone of $24.5 \pm 0.53 \mathrm{~mm}$ and $20.0 \pm 0.31 \mathrm{~mm}$, respectively against $S$. aureus. ${ }^{17}$ Naziri et al reported that peel extracts of sour and sweet pomegranate cause zone inhibition of 15.3 to 25.7 $\mathrm{mm}$ and 16.0 to $25.3 \mathrm{~mm}$, respectively, against $S$. aureus at 1 to $8 \mathrm{mg} /$ disc. $^{18}$ Melendez and Capriles demonstrated that pomegranate extract produced inhibition zone sizes of $22 \mathrm{~mm}$

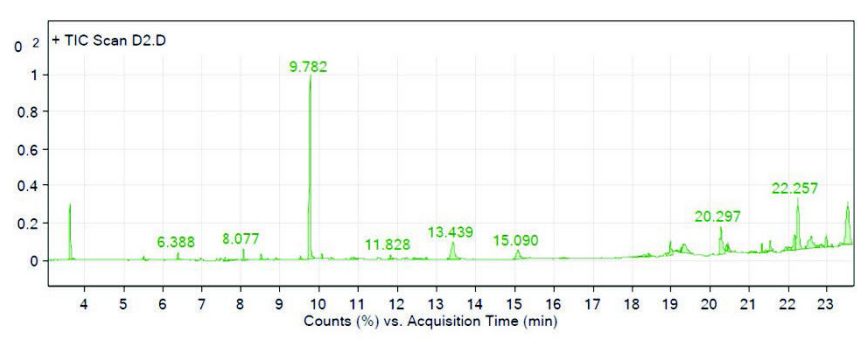

Figure 1. GC-MS Chromatogram of Ethanolic Extract of the Pomegranate Peel.

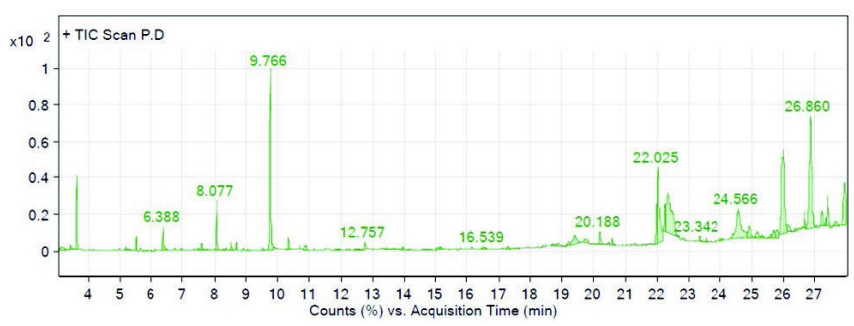

Figure 2. GC-MS Chromatogram of Ethanolic Extract of the Pomegranate Seed. for S. aureus. ${ }^{19}$ Mathabe et al showed that methanol, ethanol, acetone, and water extracts of pomegranate had activities against S. aureus, showing inhibition zones of 27.0 to 29.3 $\mathrm{mm} \cdot{ }^{20}$

The MIC and MBC values showed the antibacterial activity of pomegranate extract against both P. aeruginosa and S. aureus, while the highest effect belonged to peel extract. This finding was consistent with previous report. Dahham et al assessed the antimicrobial effect of alcoholic extract of seed, fruit, peel, and juice of pomegranate on specific bacteria including $S$. aureus and reported that the pomegranate peel extract have the greatest antimicrobial activity. ${ }^{21}$ Naziri et al reported that methanolic pomegranate peel extract has a stronger effect on gram-positive bacteria than gram-negative bacteria. So that $S$. aureus has highest sensitivity to the methanolic extracts of sour and sweet pomegranate peels. ${ }^{18}$ Kanatt et al suggested that addition of pomegranate peel extract to popular chicken meat products enhanced its shelf life due to its good antimicrobial activity against $S$. aureus. ${ }^{22}$ This variable sensitivity of bacteria to extracts of various parts of the plant is due to variable composition of extracts. ${ }^{16}$ Negi et al extracted pomegranate peels with different polar solvents at room temperature and found their antibacterial activity against $P$. aeruginosa and S. aureus. ${ }^{23}$ Duman et al reported that the MICs values for active pomegranate extracts against tested bacteria such as $S$. aureus and $P$. aeruginosa ranged between 40 and $>90 \mu \mathrm{g} /$ $\mathrm{mL} .{ }^{24}$ Braga et al showed that pomegranate extracts inhibit or delay $S$. aureus growth at 0.01 to $1 \% \mathrm{v} / \mathrm{v}$ concentrations. ${ }^{25} \mathrm{Al}-$ Zoreky found that methanolic extract of pomegranate peels was a potent inhibitor for some bacteria including S. aureus. ${ }^{26}$ In a study of antimicrobial activity of few medicinal plants against certain drug-resistant bacteria of clinical origin, broad-spectrum antimicrobial activity was observed in ethanolic extracts of pomegranate. ${ }^{27}$ It has been reported that water, ethanolic and butanolic extracts of pomegranate have antimicrobial activities against Escherichia coli, $P$. aeruginosa 
Table 2. Comparison of Zone of Inhibition Diameter $(\mathrm{mm})$ of Pomegranate Extracts and Tested Antibiotic Discs Against Standard and Clinically Isolated Bacteria

\begin{tabular}{|c|c|c|c|c|}
\hline & $\begin{array}{l}\text { Seed Extract } \\
(9 \mathrm{mg} / \text { disc })\end{array}$ & $\begin{array}{l}\text { Peel Extract } \\
(9 \mathrm{mg} / \text { disc })\end{array}$ & $\begin{array}{l}\text { Tetracycline } \\
(0.03 \mathrm{mg} / \text { disc })\end{array}$ & $\begin{array}{l}\text { Chloramphenicol } \\
\text { (0.03 mg/disc) }\end{array}$ \\
\hline P. aeruginosa (clinically isolates) & $19.3 \pm 1.6^{\mathrm{Aa}}$ & $27.3 \pm 1.4^{\mathrm{Ba}}$ & $15.3 \pm 2.9^{\mathrm{Ca}}$ & $10.8 \pm 1.8^{\mathrm{Da}}$ \\
\hline P. aeruginosa (PTCC 1430) & $18.7 \pm 1.0^{\mathrm{Aa}}$ & $22.5 \pm 1.1^{\mathrm{Ab}}$ & $12.1 \pm 0.3^{\mathrm{Bb}}$ & $13.6 \pm 0.6^{\mathrm{Ba}}$ \\
\hline S. aureus (clinically isolates) & $19.2 \pm 1.3^{\text {Аа }}$ & $27.5 \pm 1.0^{\mathrm{Ba}}$ & $15.7 \pm 3.8^{\text {Аа }}$ & $16.4 \pm 2.9^{\mathrm{Ab}}$ \\
\hline S. aureus (PTCC 1112) & $22.0 \pm 0.4^{\mathrm{Ab}}$ & $25.3 \pm 0.3^{\mathrm{Ba}}$ & $21.6 \pm 0.6^{A c}$ & $20.3 \pm 0.5^{\mathrm{Ac}}$ \\
\hline
\end{tabular}

Means $( \pm \mathrm{SD})$ within a row with different superscript letters $(\mathrm{A}, \mathrm{B}, \mathrm{C}, \mathrm{D})$ denote significant differences $(P<0.05)$.

Means $( \pm \mathrm{SD})$ within a column with different superscript letters $(\mathrm{a}, \mathrm{b}, \mathrm{c}, \mathrm{d})$ denote significant differences $(P<0.05)$.

Table 3. MICs and MBCs Values of Pomegranate Extracts and Tested Antibiotics Against Standard and Clinically Isolated Bacteria (mean \pm SD)

\begin{tabular}{|c|c|c|c|c|c|c|c|c|}
\hline & \multicolumn{4}{|l|}{ MIC } & \multicolumn{4}{|l|}{ MBC } \\
\hline & $\begin{array}{l}\text { Seed Extract } \\
(\mathrm{mg} / \mathrm{mL})\end{array}$ & $\begin{array}{l}\text { Peel Extract } \\
(\mathrm{mg} / \mathrm{mL})\end{array}$ & $\begin{array}{l}\text { Tetracycline } \\
(\mu \mathrm{g} / \mathrm{mL})\end{array}$ & $\begin{array}{l}\text { Chloramphenicol } \\
(\mu \mathrm{g} / \mathrm{mL})\end{array}$ & $\begin{array}{l}\text { Seed Extract } \\
(\mathrm{mg} / \mathrm{mL})\end{array}$ & $\begin{array}{l}\text { Peel Extract } \\
(\mathrm{mg} / \mathrm{mL})\end{array}$ & $\begin{array}{l}\text { Tetracycline } \\
(\mu \mathrm{g} / \mathrm{mL})\end{array}$ & $\begin{array}{l}\text { Chloramphenicol } \\
(\mu \mathrm{g} / \mathrm{mL})\end{array}$ \\
\hline P. aeruginosa (clinically isolates) & $32.5 \pm 11.6$ & $16.2 \pm 5.8$ & $25.3 \pm 2.9$ & $67.2 \pm 7.1$ & $52.5 \pm 17.7$ & $30.0 \pm 10.1$ & $>1250 \pm 8.6$ & $>1250 \pm 5.5$ \\
\hline P. aeruginosa (PTCC 1430) & $25.0 \pm 0.0$ & $12.5 \pm 0.1$ & $14.6 \pm 2.3$ & $45.1 \pm 4.6$ & $50.0 \pm 0.0$ & $25.0 \pm 0.0$ & $962.7 \pm 5.0$ & $1019.4 \pm 2.7$ \\
\hline S. aureus (clinically isolates) & $55.0 \pm 15.2$ & $37.5 \pm 12.7$ & $6.7 \pm 3.3$ & $9.0 \pm 5.9$ & $75.0 \pm 25.4$ & $70.0 \pm 24.9$ & $132.8 \pm 5.1$ & $>1250 \pm 2.9$ \\
\hline S. aureus (PTCC 1112) & $50.0 \pm 0.0$ & $25.0 \pm 0.0$ & $2.3 \pm 0.0$ & $3.4 \pm 0.1$ & $100.0 \pm 0.0$ & $50.0 \pm 0.0$ & $125.0 \pm 0.0$ & $>1250 \pm 1.5$ \\
\hline
\end{tabular}

and methicillin-resistant S. aureus. ${ }^{8}$ In another study, pomegranate peel fractions showed higher antimicrobial activities (inhibition zone) than the against $S$. aureus and $P$. aeruginosa but not E. coli. ${ }^{28}$ Melendez and Capriles have also reported that extracts from Pomegranate fruits possess strong in vitro antibacterial activity against many bacterial strains tested including E. coli, S. aureus, Enterobacter spp., Bacillus spp., and Micrococcus spp. ${ }^{19}$ Voravuthikunchai et al reported that chloroform, ethanol and water extract of pomegranate showed high activity against strains of E. coli O157:H7. One important factor affecting the MIC is the difference in the composition of extracts. ${ }^{29}$ The composition of extract is influenced by the geographical location of the plant, season of harvesting, age of plant, growth stage, method of drying, and extraction technique. ${ }^{16}$

As per various literature reports, $P$. grantum contains chemical constituents like, ellagitannins, phenols, tannins, punicic acid, flavonoids, anthocyanins, estrogenic flavonoids and flavones. ${ }^{30,31}$ Some of these compounds have been found to own antibacterial activity. The tannin-rich ellagitannins and phenolic acids of pomegranate may have antibacterial activity. ${ }^{8,29,32}$ It has been suggested that phenolic compounds, especially gallic acid, were the most important and active compounds against bacteria. ${ }^{24}$ Pomegranate contains large amounts of tannins (25\%) and antibacterial activity may be indicative of the presence of secondary metabolites. ${ }^{17}$ Carvacrol methyl ether is another constituent of pomegranate with confirmed antimicrobial effects. Thymol is an isomer of carvacrol, showing its antimicrobial activity. ${ }^{33}$ The inhibitory effect of these compounds could be related to adsorption to cell membranes, interaction with enzymes, substrate and metal ion deprivation. ${ }^{34}$ It has been suggested that pomegranate extract enhanced the activity of some antibiotics including chloramphenicol, gentamicin, ampicillin, tetracycline, and oxacillin against 30 clinical isolates of S. aureus. ${ }^{25}$ The synergistic effect from the association of antibiotic with pomegranate extracts against resistant bacteria may lead to new choices for the treatment of infectious diseases.

\section{Conclusions}

According to the findings of this study, the pomegranate peel and seed extracts showed antibacterial activities against bacterial isolates. However, pomegranate peel extract had a stronger antibacterial effect than pomegranate seed extract. Therefore, further studies including cell toxicity assay and in vivo investigations are recommended.

\section{Authors' Contributions}

Conception and design of the study: RG; Acquisition of data and doing the laboratory phase: $\mathrm{YN}$; Analysis and interpretation of data: $\mathrm{YN}, \mathrm{RG}$, RM, and MF. All authors contributed to drafting the article and revising it critically for important intellectual content.

\section{Conflict of Interest Disclosures}

The authors declare that there is no conflict of interest regarding the publication of this article.

\section{Acknowledgements}

The authors would like to thank colleagues at the Molecular Biology Research Center, Systems Biology and Poisonings Institute, Baqiyatallah University of Medical Sciences for their kind and generous assistance.

\section{References}

1. Palavutitotai $N$, Jitmuang $A$, Tongsai $S$, Kiratisin $P$, Angkasekwinai N. Epidemiology and risk factors of extensively drugresistant Pseudomonas aeruginosa infections. PLoS One. 2018;13(2):e0193431. doi:10.1371/journal.pone.0193431

2. Hosseini MJ, Kiarsi M, Golmohammadi R, Sadripour R. Antibiotic Resistance pattern of bacteria isolated from nosocomial infection in internal surgery and neurosurgery intensive care unit (NICU) at a tertiary care hospital in Tehran, Iran. Biosci Biotech Res Asia. 2017;14(3):1095-1102. doi:10.13005/bbra/2547

3. Ranjbar R, Tolon SS, Sami M, Golmohammadi R. Detection of plasmid-mediated qnr genes among the clinical quinolone-resistant Escherichia coli strains isolated in Tehran, Iran. Open Microbiol J. 


\section{8;12:248-253. doi:10.2174/1874285801812010248}

4. Choopani A, Golmohmmadi R, Rafati H, Imani Fooladi AA. Prevalence of Staphylococcus aureus strains isolated from wound infection and drug sensitivity pattern, Tehran-Iran (2006-07). J Gorgan Univ Med Sci. 2012;14(3):135-140.

5. Kian B, Mirnejad R, Mirkalantari S, Moradli G, Golmohammadi R. Molecular genotyping of Acinetobacter baumannii species isolated from patients in Tehran, Iran, by repetitive element PCR fingerprinting. Iran J Pathol. 2018;13(2):144-150.

6. Alanis AD, Calzada F, Cervantes JA, Torres J, Ceballos GM. Antibacterial properties of some plants used in Mexican traditional medicine for the treatment of gastrointestinal disorders. J Ethnopharmacol. 2005;100(1-2):153-157. doi:10.1016/j. jep.2005.02.022

7. Derakhshan Z, Ferrante $M$, Tadi $M$, et al. Antioxidant activity and total phenolic content of ethanolic extract of pomegranate peels, juice and seeds. Food Chem Toxicol. 2018;114:108-111. doi:10.1016/j.fct.2018.02.023

8. Reddy MK, Gupta SK, Jacob MR, Khan SI, Ferreira D. Antioxidant, antimalarial and antimicrobial activities of tannin-rich fractions, ellagitannins and phenolic acids from Punica granatum L. Planta Med. 2007;73(5):461-467. doi:10.1055/s-2007-967167

9. Devatkal SK, Jaiswal P, Jha SN, Bharadwaj R, Viswas KN. Antibacterial activity of aqueous extract of pomegranate peel against Pseudomonas stutzeri isolated from poultry meat. J Food Sci Technol. 2013;50(3):555-560. doi:10.1007/s13197-0110351-y

10. Vasconcelos LC, Sampaio MC, Sampaio FC, Higino JS. Use of Punica granatum as an antifungal agent against candidosis associated with denture stomatitis. Mycoses. 2003;46(5-6):192196.

11. Houston DMJ, Bugert JJ, Denyer SP, Heard CM. Potentiated virucidal activity of pomegranate rind extract (PRE) and punicalagin against Herpes simplex virus (HSV) when co-administered with zinc (II) ions, and antiviral activity of PRE against HSV and aciclovirresistant HSV. PLoS One. 2017;12(6):e0179291. doi:10.1371/ journal.pone. 0179291

12. Gavanji S, Larki B, Bakhtari A. The effect of extract of Punica granatum var. pleniflora for treatment of minor recurrent aphthous stomatitis. Integr Med Res. 2014;3(2):83-90. doi:10.1016/j. imr.2014.03.001

13. Sharifiyan F, Movahedian-Attar A, Nili N, Asgary S. Study of pomegranate (Punica granatum L.) peel extract containing anthocyanins on fatty streak formation in the renal arteries in hypercholesterolemic rabbits. Adv Biomed Res. 2016;5:8. doi:10.4103/2277-9175.175241

14. Jorgensen JH, Turnidge JD. Susceptibility test methods: dilution and disk diffusion methods. In: Jorgensen J, Pfaller M, Carroll K, eds. Manual of Clinical Microbiology. 11th ed. Washington, DC: American Society of Microbiology; 2015:1253-1273.

15. Andrews JM. Determination of minimum inhibitory concentrations. J Antimicrob Chemother. 2001;48 Suppl 1:5-16.

16. Hajifattahi F, Moravej-Salehi E, Taheri M, Mahboubi A, Kamalinejad M. Antibacterial effect of hydroalcoholic extract of Punica granatum Linn. petal on common oral microorganisms. Int J Biomater. 2016;2016:8098943. doi:10.1155/2016/8098943

17. Malviya S, Arvind, Jha A, Hettiarachchy N. Antioxidant and antibacterial potential of pomegranate peel extracts. J Food Sci Technol. 2014;51(12):4132-4137. doi:10.1007/s13197-0130956-4
18. Naziri Z, Rajaian H, Firouzi R. Antibacterial effects of Iranian native sour and sweet pomegranate (Punica granatum) peel extracts against various pathogenic bacteria. Iran J Vet Res. 2012;13(4):282-288. doi:10.22099/ijvr.2012.606

19. Melendez PA, Capriles VA. Antibacterial properties of tropical plants from Puerto Rico. Phytomedicine. 2006;13(4):272-276. doi:10.1016/j.phymed.2004.11.009

20. Mathabe MC, Nikolova RV, Lall N, Nyazema NZ. Antibacterial activities of medicinal plants used for the treatment of diarrhoea in Limpopo Province, South Africa. J Ethnopharmacol. 2006;105(12):286-293. doi:10.1016/j.jep.2006.01.029

21. Dahham SS, Ali MN, Tabassum H, Khan M. Studies on antibacterial and antifungal activity of pomegranate (Punica granatum L.). Am Eurasian J Agric Environ Sci. 2010;9(3):273-281.

22. Kanatt SR, Chander R, Sharma A. Antioxidant and antimicrobial activity of pomegranate peel extract improves the shelf life of chicken products. Int J Food Sci Technol. 2010;45(2):216-222. doi:10.1111/j.1365-2621.2009.02124.x

23. Negi PS, Jayaprakasha GK, Jena BS. Antioxidant and antimutagenic activities of pomegranate peel extracts. Food Chem. 2003;80(3):393-397. doi:10.1016/S0308-8146(02)00279-0

24. Duman AD, Ozgen M, Dayisoylu KS, Erbil N, Durgac C. Antimicrobial activity of six pomegranate (Punica granatum L.) varieties and their relation to some of their pomological and phytonutrient characteristics. Molecules. 2009;14(5):1808-1817. doi:10.3390/molecules14051808

25. Braga LC, Shupp JW, Cummings C, et al. Pomegranate extract inhibits Staphylococcus aureus growth and subsequent enterotoxin production. J Ethnopharmacol. 2005;96(1-2):335339. doi:10.1016/j.jep.2004.08.034

26. Al-Zoreky NS. Antimicrobial activity of pomegranate (Punica granatum L.) fruit peels. Int J Food Microbiol. 2009;134(3):244248. doi:10.1016/j.ijfoodmicro.2009.07.002

27. Ahmad I, Beg AZ. Antimicrobial and phytochemical studies on 45 Indian medicinal plants against multi-drug resistant human pathogens. J Ethnopharmacol. 2001;74(2):113-123.

28. Opara LU, Al-Ani MR, Al-Shuaibi YS. Physico-chemical properties, vitamin $\mathrm{C}$ content, and antimicrobial properties of pomegranate fruit (Punica granatum L.). Food Bioproc Tech. 2009;2(3):315-321. doi:10.1007/s11947-008-0095-5

29. Voravuthikunchai SP, Sririrak T, Limsuwan S, Supawita T, lida T, Honda T. Inhibitory effects of active compounds from Punica granatum pericarp on verocytotoxin production by enterohemorrhagic Escherichia coli O157: H7. J Health Sci. 2005;51(5):590-596. doi:10.1248/jhs.51.590

30. Fateh MV, Ahmed S, Ali M, Bandyopadhyay S. A review on the medicinal importance of pomegranate. J Pharm sci. 2013;3(4):2325. doi:10.5530/rjps.2013.4.3

31. Heber D, Schulman RN, Seeram NP. Pomegranates: ancient roots to modern medicine. CRC Press; 2006.

32. Prashanth D, Asha MK, Amit A. Antibacterial activity of Punica granatum. Fitoterapia. 2001;72(2):171-173. doi:10.1016/S0367326X(00)00270-7

33. Bhandari PR. Pomegranate (Punica granatum L). Ancient seeds for modern cure? Review of potential therapeutic applications. International Journal of Nutrition, Pharmacology, Neurological Diseases. 2012;2(3):171-184. doi:10.4103/2231-0738.99469

34. Scalbert A. Antimicrobial properties of tannins. Phytochemistry. 1991;30(12):3875-3883. doi:10.1016/0031-9422(91)83426-L 